\title{
Material Research of Rotary Sealing Device for Combined Cutting System
}

\author{
Zeng Rui ${ }^{1,2}$, Zhang Yong ${ }^{2}$, Lin Zhenrong ${ }^{2}$ and Wang Lulu ${ }^{1}$ \\ ${ }^{1}$ College of Field Engineering, PLA Univ. of Sci. \& Tech., Nanjing 210007, China \\ ${ }^{2}$ Department of Airfield Engineering, Air Force Logistics College, Xuzhou 221000, China
}

\begin{abstract}
In order to solve the rotary sealing problem of rotary shaft in drum shearer combined cutting system, the material and structure of combined cutting system rotary sealing device needs to be selected and designed. In the paper, the rotary sealing structure of four grades in series was designed first, and then the material of NBR-40 and PTFE 4FT-4 under the separate static and dynamic sealing tests were carried out on the combined tooth-slip-ring sealing test-bed. The tests show that the NBR-40 O-Ring with PTFE 4FT-4 tooth-slip-ring has no low-pressure leakage problem and low leakage in the sealing progress, the sealing effect of which is the best.
\end{abstract}

\section{Introduction}

The high pressure water jet which is supplied to the nozzle of combined cutting drum needs to flow through the hollow rotary shaft of the drum. The leakage of high pressure water can lead to a significant reduction in water pressure, which can not reach the requirements of cutting hard coal rock, and the leakage of water flow into the rocker gear box will greatly affect the gear transmission[1]. The sealing form of drum shearer \& water jet combined cutting system's cutting part is a typical high pressure dynamic rotary sealing, and to solve the problem of high pressure water sealing is very important. On the premise of meeting the requirements of the high sealing pressure, the starting performance and the lubrication effect of the drum rotary shaft must be considered.

\section{Structure of rotary sealing device}

The rotary sealing device structure design requirements of combined cutting system are as follows:

(1) The structure is simple and the size is small, and should be matched with rotary shaft parameters.

(2) Can withstand more than 40MPa sealing pressure.

(3) Can withstand 50 $\mathrm{r} / \mathrm{min}$ rotational wear.

(4) The sealing device is reliable, long service life and easy to replace.

The overall structure of the rotary seal designed in this paper is shown in Figure 1. First of all, the rotary sealing device did not change the basic structure of spray system of shearer, and only the end of the rotary shaft was lengthened $30 \mathrm{~mm}$, which could be modified in the coal mining machine directly. The high pressure water flowing through the hollow rotary shaft could take away a lot of friction heat, which effectively improved the seal working environment and increased the sealing life. Secondly, the four grades in series sealing structure model was adopted. The four grades in series sealing was separated by sealing sleeves and the internal contact pressure balance was adjusted, which avoided the rotary shaft of uneven wear. If the first grade sealing failed, part of the high pressure water could drop from the first leakage point to give a warning, and then the second grade sealing began to work, and so on. four grades in series sealing structure can extend the service life of the rotary sealing effectively, and reduce the times of sealing replacement. The wear of the sealing ring can be detected at any time, and the damaged sealing also has the role of resisting the pressure for the next grade sealing.

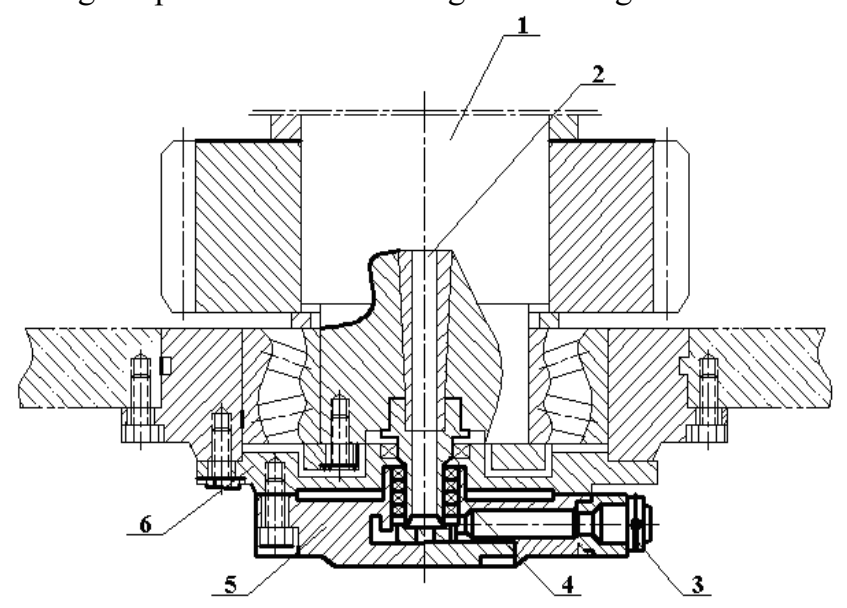

1-drum shaft; 2 - stainless steel pipe; 3 - pipe connection; 4- four grades in series sealing; 5 - end cap; 6 - inner end cap

Figure 1. Structure of rotary sealing device 
After comprehensive comparison and selection of various types of rotary sealing[2 4], the KNOR361 series tooth-sliding-ring of Xuzhou Kono seal Co. Ltd was chosen to use, shown in Figure.2.

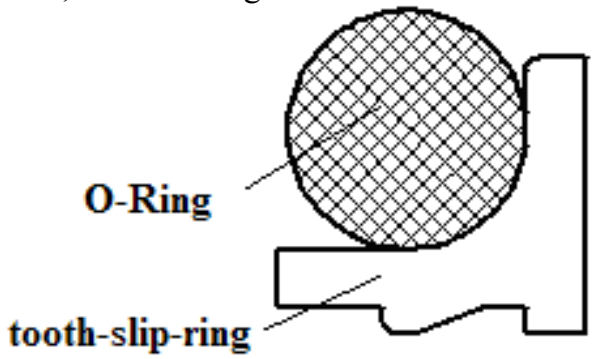

Figure 2. Combined tooth-slip-ring sealing

The KNOR361 series tooth ring lip is thin and easy to be deformed. It can produce enough deformation to compensate for wear under the elastic force of $\mathrm{O}$ type ring. The tooth ring side can block the $\mathrm{O}$ ring to prevent from being squeezed out, which improves the overall sealing capacity of tolerance and pressure.

\section{Material test and result analysis}

\subsection{Building test-bed of combined sealing}

\subsubsection{Structure of test-bed of combined sealing}

In the combined cutting system, rotary sealing department working environment is high pressure, medium rotation rate and room temperature, so the composite materials of high pressure and strong wear resistance tend to be chosen. According to the criterion of $\mathrm{HG} / \mathrm{T}$ 2579-2008 and the practical experience[2,5,6], the material of NBR-40 and PTFE 4FT-4 are consistent with the requirements of the part of rotary sealing. The testbed of combined tooth-slip-ring sealing was built to test the practical results of the NBR-40 and PTFE 4FT-4, shown in Figure.3.

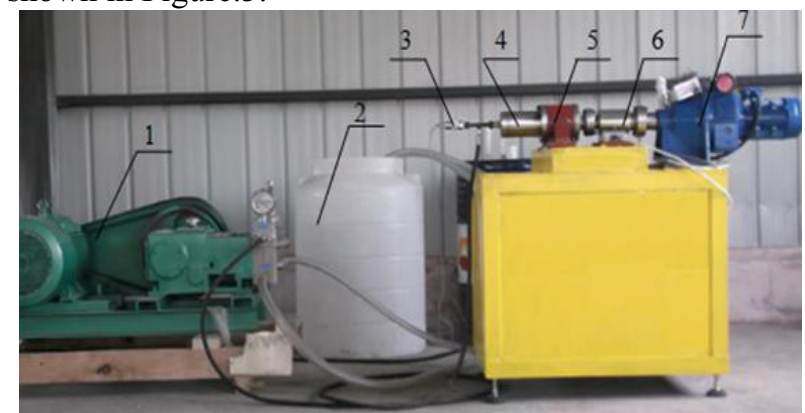

1- high pressure water pump; 2- water tank; 3- pressure pickup; 4- rotary sealing part;5-Coupling part; 6- torque sensor ; 7- electric motor

Figure 3. Test-bed of combined tooth and slip-ring sealing

\subsubsection{The components and functions of the test-bed}

(1) The 3SP40-A series high-precision high pressure pump provides a stable $0 \sim 80 \mathrm{MPa}$ water jet pressure, and the pressure of the pump's outlet can be adjusted.

(2) The water tank is used to provide experimental water.

(3) The measurement range of JNBP-2-100MPa pressure pickup is $0 \sim 100 \mathrm{MPa}$. Its output signal is the voltage signal to measure the pressure of the water outlet

(4) The rotary sealing part adopts the four grades in series sealing structure model, and single sealing is toothsliding-ring combined sealing, shown in Figure.4. The main purpose of the test is to test the sealing performance of the rotary sealing.

(5) The coupling part is composed of transmission shaft and transmission cylinder, which is connected with the rotary sealing part to transfer power to the rotary sealing system and plays the role of supporting and protecting.

(6) The measurement range of JN-DNJ-100 torque sensor is $0 \sim 100 \mathrm{~N} \cdot \mathrm{m}$. Signal output is a kind of low voltage standard signal, which is used to measure the torque of the output shaft.

(7) The Y2-B590-4 electric motor is the power device of the system, which is used to simulate the rotation of the drum shaft.

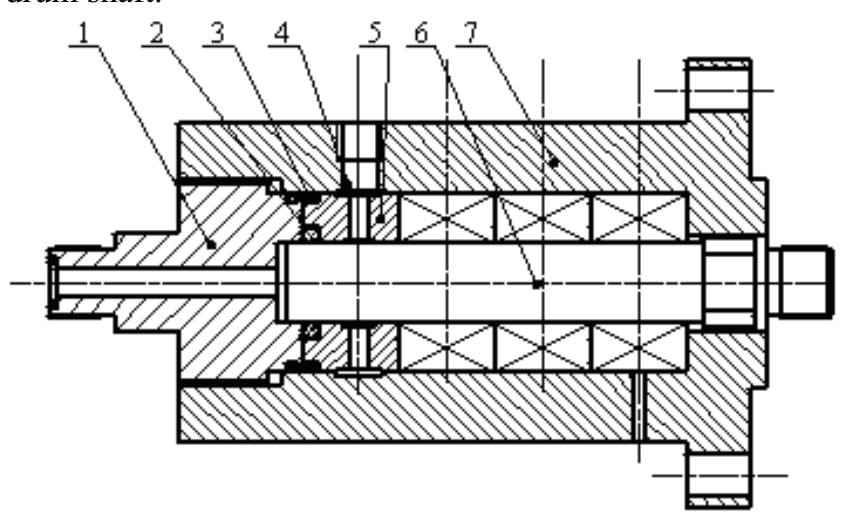

1-water inlet; 2- single sealing; 3- Static seal ring; 4-leak hole; 5- guide bushing; 6- rotary shaft; 7 - Sealing cylinder

Figure 4. Rotary sealing device structure of test-bed

\subsection{Static sealing leakage test}

\subsubsection{Static sealing leakage test scheme}

In the static sealing leakage test, the motor which simulated the rotation of the drum shaft did not start, while the high pressure water pump started. The material of NBR-40 (group A) and PTFE 4FT-4 (group B) rotary shaft combined tooth-slip-ring sealing were test to check the sealing effect. In order to facilitate the assessment of the sealing effect, the sealing parts were sealed continuously after 4 hours and the seal leakage per hour under different water pressure as the standard. It was found that when the leakage of water was more than 5500 $\mathrm{mL} / \mathrm{h}$, high pressure pump would have obvious pressure and power fluctuations, which could seem to be sealing failure. 


\subsubsection{Static sealing leakage test result analysis}

Under static sealing, when the pressure was in the middle and low pressure stage of $10 \mathrm{MPa}$ and $20 \mathrm{MP}$, the group $\mathrm{A}$ and group $B$ were all reliable sealing in 4 hours of continuous static sealing, but the group B had a small amount of leakage and the total leakage is about $65 \mathrm{~mL} / \mathrm{h}$. This is because the hardness of the PTFE 4FT-4 is relatively large, and it is difficult to produce enough deformation to form the tight sealing tape in low pressure. But the leakage too small to effect on the sealing performance.

When the pressure was in the high pressure stage of $30 \mathrm{MPa}$ and $40 \mathrm{MPa}$, group B formed a tight sealing tape gradually and its leakage phenomenon disappeared. After 4 hours' continuous sealing, there was no leakage basically. In the high pressure stage, The first grade sealing ring of group Acould only maintain about 20 minutes of stable seal, and about 60minutes later the overall sealing failed.

In order to solve the problem of group A and group B, the NBR-40 O-Ring with PTFE 4FT-4 tooth-slip-ring was adopted as group C. In the static seal leakage test, the group $\mathrm{C}$ demonstrated excellent sealing performance. In the middle and low pressure stage, Total leakage of group $\mathrm{C}$ was only $8 \mathrm{~mL} / \mathrm{h}$, and in the high pressure stage, there was no leakage as group B.

\subsection{Dynamic sealing leakage test}

\subsubsection{Dynamic sealing leakage test scheme}

In dynamic sealing leakage test, the high pressure water pump was started and the pressure was adjusted to 40Mpa. The motor is started to simulate the rotation of the drum shaft, and 7 different speed segments are set in turn. Because the group A was not suitable for the high pressure seal of the rotating sealing part, only group B and group $\mathrm{C}$ were test in the dynamic sealing leakage test. The group $\mathrm{B}$ and the group $\mathrm{C}$ were continuously work for 4 hours at 7 different rotational speeds, and the relation of rotate speed and leakage was shown in Figure. 5

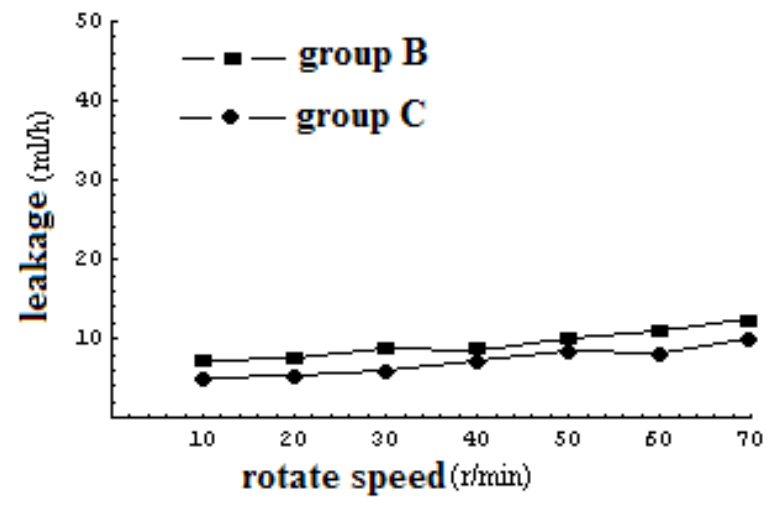

Figure 5. Relation of rotate speed and leakage under dynamic sealing

\subsubsection{Dynamic sealing leakage test result analysis}

Both group B and group C could meet the requirements of dynamic sealing leakage test, and Leakage was only about $10 \mathrm{~mL} / \mathrm{h}$, which was belong to a minor leak, and the slight leakage could be beneficial to the seal itself.The sealing leakage rate of group B was slightly higher than group C. This showed that the NBR-40 seal ring produced more pressing force to tooth ring under the pressure of $40 \mathrm{MPa}$, which caused the lower rotary seal leakage and better sealing effect of group $\mathrm{C}$.

The signals collected by the torque sensor were sent to the dynamic signal acquisition instrument which was DASP-V10, shown in Figure.6. Tte statistical of the two groups of signals was processed by DASP-V10 with its own signal analysis software, and the average torque of group B was $34.732 \mathrm{~N} \cdot \mathrm{m}$ and group $\mathrm{C}$ was $39.401 \mathrm{~N} \cdot \mathrm{m}$. The resistance of the group B to the rotation of the drum shaft was slightly less than that of the group $\mathrm{C}$, because the friction factor of PTFE 4FT-4 was less than the NBR40 .

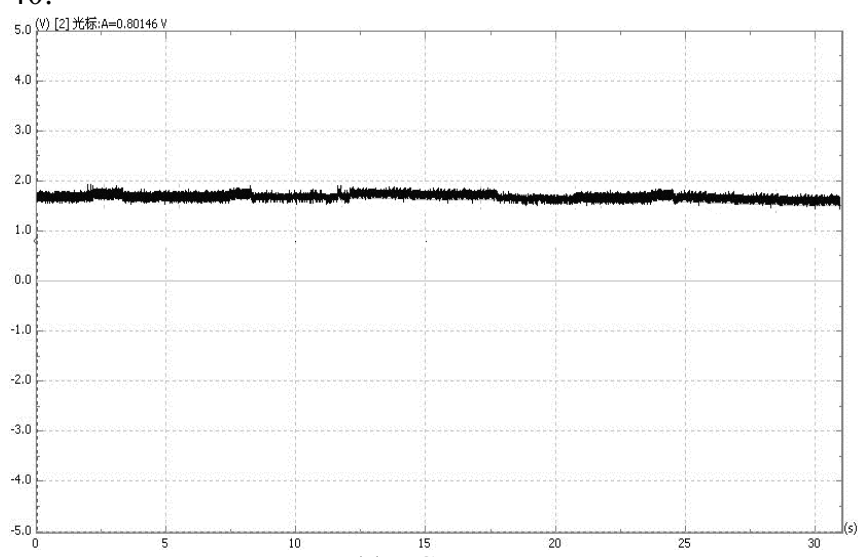

(a) Group B

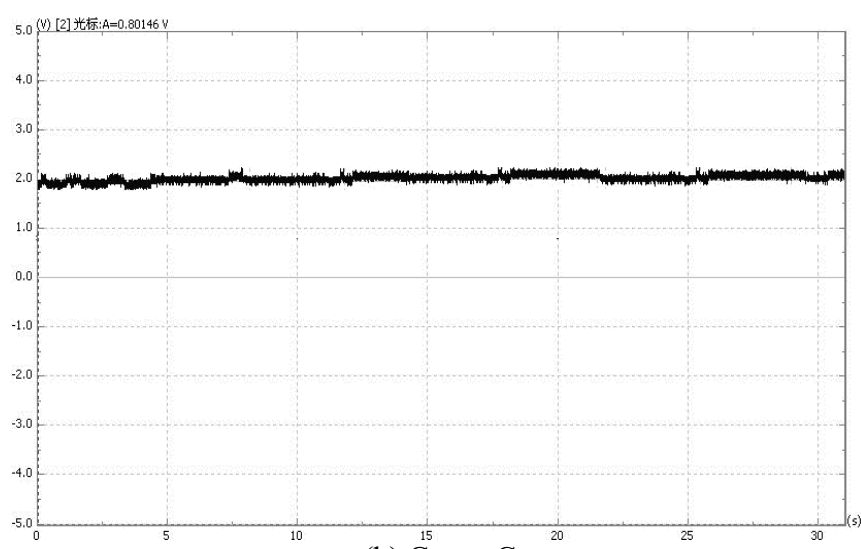

(b) Group C

Figure 6. DASP-V10 output curve of dynamic sealing

\subsection{FEM Analysis of combined tooth-slip-ring sealing}

In the process of finite element analysis, in view of the complexity of the boundary conditions, the rotating shaft and seal guide sleeve of the sealing structure are analyzed as a whole, which is shown in Figure.7. 


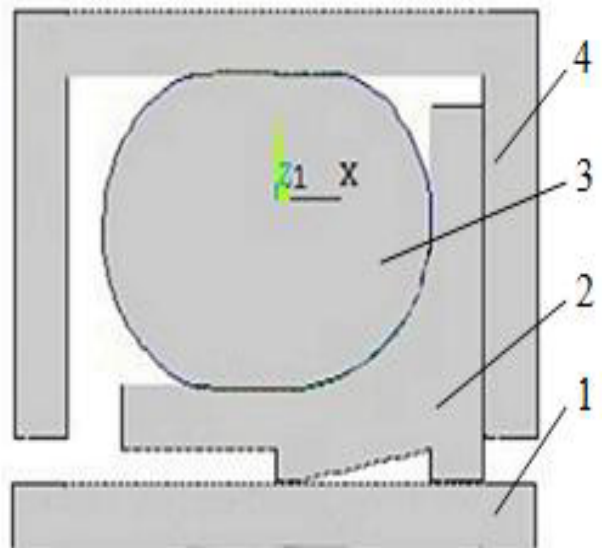

1- Rotation axis; 2- Toothed ring; 3-O ring; 4- Seal guide sleeve Figure 7. Geometric model of combined seal

According to the contact of the definition of standards, the $\mathrm{O}$ ring is the contact body, and the slip ring is the target. Rotary shaft seal guide sleeve and the slip ring use the linear solid element PLANE42 simulation, and rubber unit adopts super elastic element PLANE182 simulation, which is shown in Figure 8.

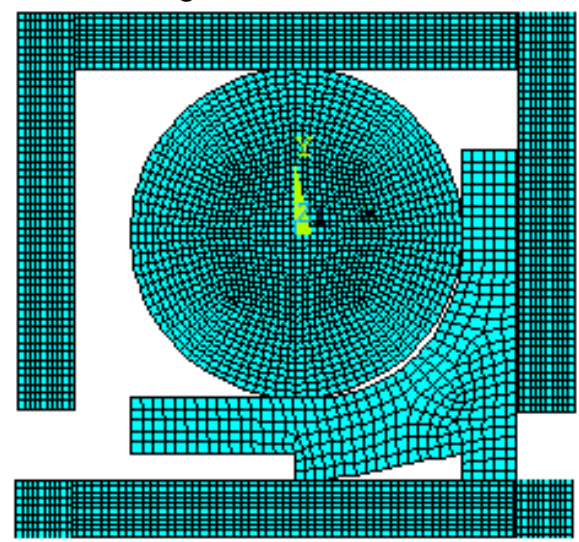

Figure 8. FEM model of combined seal

Under the loading condition, the equivalent stress distribution of tooth ring is shown in Figure 9 and the tooth contact pressure nephogram of slip ring combined seal is shown in Figure 10.

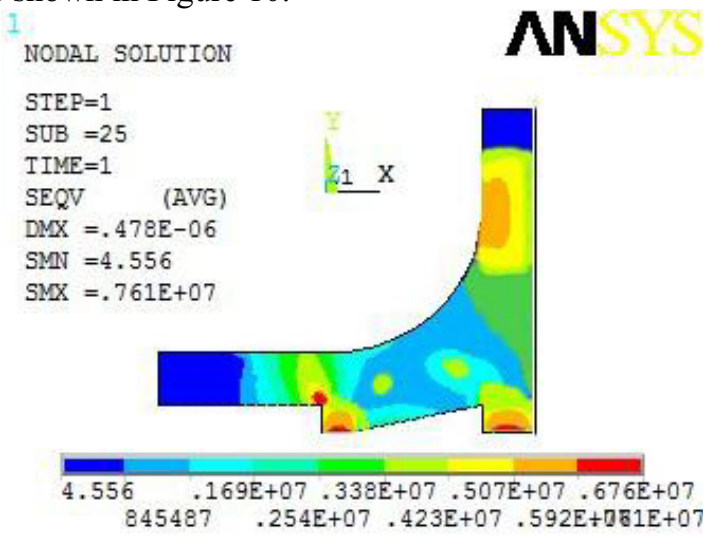

Figure 9. Von-mises stress distribution of sliding ring

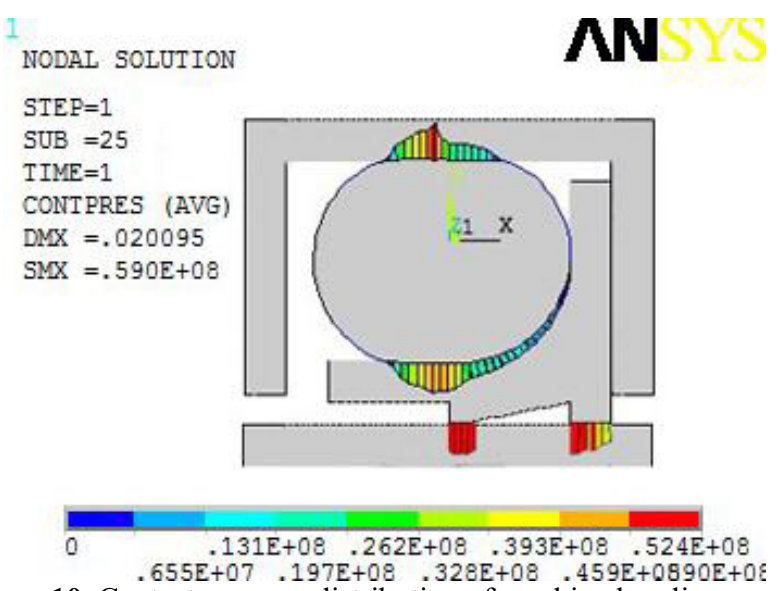

Figure 10. Contact pressure distribution of combined sealing

From the Figure 9 and 10, we can see that the main sealing lip and a secondary sealing lip at the tooth ring exist some stress concentration. The stress distribution of other positions is relatively uniform, and the stress value is small. From the sealing point of view, due to the stress concentration of the sealing lip, the contact surface produced a high contact pressure to achieve good sealing effect.

\section{Conclusions}

(1) The rotary sealing device did not change the basic structure of spray system of shearer, and only the end of the rotary shaft was lengthened $30 \mathrm{~mm}$, which could be modified in the coal mining machine directly.

(2) The rotary shaft tooth-slip-ring made by NBR-40 could not meet the sealing requirements of combined cutting work pressure, while the PTFE 4FT-4 could, but a small amount of leakage occured at low pressure.

(3) The NBR-40 O-Ring with PTFE 4FT-4 tooth-slipring had no low-pressure leakage problem and low leakage in the sealing progress. Although the resistance to rotation of the drum shaft is larger than full PTFE 4FT4 material, comprehensive consideration of various factors, the group $\mathrm{C}$ should be selected.

\section{References}

1. M.S. Cui, J.J. Sun. Coal Industry, 2,21(1993).

2. Q. Dong. Journal of China University of Mining and Technology, 4, 54(2013).

3. J.C. Zhang, Q.M. Wang, H.F. Li. Lubrication Engineering, 36, 59(2011).

4. S.H. Chen. Mechanical Engineer, 8, 19(2000).

5. Markus, Henzler. Lubrication Engineering. 35, 93(2010).

6. Z.F. Li, C.H. Gao, Y.X. Lin. Journal of plastics industry, 33,13(2005). 